\title{
Effect of advanced oxidation protein products on the proliferation and osteogenic differentiation of rat mesenchymal stem cells
}

\author{
NAN SUN ${ }^{1 *}$, LI YANG $^{1 *}$, YINGBIN LI $^{2}$, HUA ZHANG $^{1}$, HONG CHEN $^{1}$, \\ DUAN LIU ${ }^{1}$, QINGNAN $\mathrm{LI}^{2}$ and DEHONG CAI ${ }^{1}$ \\ ${ }^{1}$ Department of Endocrinology, Zhujiang Hospital, Southern Medical University, Guangzhou, Guangdong 510280; \\ ${ }^{2}$ School of Life Science and Biopharmacy, Guangdong Pharmaceutical University, Guangzhou, Guangdong 510006, P.R. China
}

Received March 9, 2013; Accepted May 24, 2013

DOI: $10.3892 /$ ijmm.2013.1402

\begin{abstract}
Advanced oxidation protein products (AOPPs) as a novel marker of oxidative stress, are involved in a variety of diseases, including osteoporosis. Although a number of studies have shown the possible functions of AOPPs in biological processes, little is known about the role of AOPPs in the pathogenesis of osteoporosis. In this study, we aimed to investigate the effect of AOPPs on the proliferation and osteogenic differentiation of rat mesenchymal stem cells (MSCs). MSCs, isolated from bone marrow, were cultured in the absence or presence of AOPPs (50, 100, 200 and $400 \mathrm{mg} / \mathrm{ml})$. MTT assay was used to determine the proliferative ability of the cells. Alkaline phosphatase (ALP) activity, the mRNA expression of ALP and collagen I and bone nodule formation were detected to assess osteogenic differentiation. Reactive oxygen species (ROS) generation was analyzed with the probe 2',7'-dichlorodihydrofluorescein diacetate (DCFH-DA). The expression of receptor of advanced glycation end-products (RAGE) at the mRNA and protein level was detected by real-time PCR and western blot analysis, respectively. Compared with the control group, AOPPs inhibited MSC proliferation in a dose- and timedependent manner. Moreover, AOPPs induced a significant reduction in ALP activity, as well as a decrease in ALP and collagen I mRNA levels in the MSCs; bone nodule formation was also inhibited. Furthermore, AOPPs increased ROS generation in the MSCs, and upregulated the expression of RAGE at
\end{abstract}

Correspondence to: Professor Dehong Cai, Department of Endocrinology, Zhujiang Hospital, Southern Medical University, 253 Industrial Avenue, Guangzhou, Guangdong 510280, P.R. China E-mail: caidehongzj@gmail.com

Professor Qingnan Li, School of Life Science and Biopharmacy, Guangdong Pharmaceutical University, 280 Ring East Road, College Town, Guangzhou, Guangdong 510006, P.R. China

E-mail: liqingnangy@gmail.com

*Contributed equally

Key words: advanced oxidation protein products, proliferation, differentiation, receptor for advanced glycation end-products, reactive oxygen species the mRNA and protein level. These results suggest that AOPPs inhibit the proliferation and osteogenic differentiation of MSCs, possibly through the AOPPs-RAGE-ROS pathway; this may be an important mechanism in the development of osteoporosis.

\section{Introduction}

Osteoporosis is a skeletal disorder characterized by an imbalance between bone resorption and bone formation, culminating in fragility fractures, pain and disability (1). Although the mechanisms involved are unclear, increasing evidence indicates that oxidative stress plays a role in the pathogenesis of osteoporosis $(2,3)$. Oxidative stress is an imbalance between the free radicals and antioxidant mechanisms in biological systems and damages cellular macromolecules and functions. It can lead to an accumulation of reactive oxygen species (ROS) in the body which has adverse effects on the skeleton (4).

Advanced oxidation protein products (AOPPs) are defined as dityrosine-containing cross-linked protein products formed during oxidative stress by the action of chlorinated oxidants (5). Thus far, AOPPs have received increasing attention as novel markers of oxidative stress. There is a close correlation between AOPPs and monocyte activation markers in vivo, such as neopterin and interleukin-1 receptor (IL-1R) antagonist. AOPPs trigger the oxidative burst of human monocytes in culture (6). Evidence incidates that AOPPs increase ROS levels in human umbilical vein endothelial cells by activating nicotinamide adenine dinucleotide phosphate (NAD $(\mathrm{P}) \mathrm{H})$ oxidase, extracellular-signal-regulated kinase (ERK)1/2, p38 and nuclear factor (NF)- $\mathrm{B}$ (7).

AOPPs accumulate in the body and increase with age (8). Elevated levels of AOPPs are detected in many types of diseases, including osteoporosis (9-14). Certain studies have demonstrated that oxidative stress leads to increased levels of AOPPs in osteoblastic MC3T3-E1 cells $(15,16)$; AOPPs have been shown to inhibit the proliferation and differentiation of rat osteoblastic cells through $\mathrm{NF}-\kappa \mathrm{B}$ (17); these data suggest that AOPPs are associated with the progression of osteoporosis. However, to our knowledge, there are no studies to date on the effects of AOPPs on mesenchymal stem cells (MSCs).

Since impaired bone formation is an important mechanism involved in the pathological process of osteoporosis, the inhibition of osteoblast proliferation and the inability to form bone 
may result in osteoporosis (18). Bone cells purportedly originate from MSCs that commit to the osteogenic cell lineage, becoming osteoprogenitor cells, pre-osteoblasts, osteoblasts and osteocytes $(19,20)$. MSCs in patients with osteoporosis also have abnormal gene expression $(21,22)$. Thus, the negative effects on MSC osteogenic differentiation may aggravate the development of osteoporosis. Therefore, the aim of this study was to investigate the role of AOPPs in modulating the proliferation and osteogenic differentiation of rat bone marrowderived MSCs, as well as the possible mechanisms involved.

\section{Materials and methods}

Materials. Trypsin-EDTA, 2',7'-dichlorodihydrofluorescein diacetate (DCFH-DA), the amebocyte lysate assay kit, dexamethasone, ascorbic acid, $\beta$-glycerophosphate, alizarin red, p-nitrophenyl phosphate and 3-(4,5-dimethylthiazozyl)-2,5diphenyl tetrazolium bromide (MTT) were all obtained from Sigma (St. Louis, MO, USA). Bovine serum albumin (BSA) was from Roche Diagnostics GmbH (Mannheim, Germany); Oil Red O was purchased from Amresco, Inc. (Solon, OH, USA); the BCA assay kit was from CoWin Biotech (Beijing, China); dimethyl sulfoxide (DMSO) and TRIzol reagent were obtained from Invitrogen (Buenos Aires, Argentina); adipogenic differentiation medium, fetal bovine serum (FBS) and Dulbecco's modified Eagle's medium (DMEM) were all from HyClone (Logan, UT, USA); the PrimeScript ${ }^{\circledR}$ one step RT-PCR kit and SYBR ${ }^{\circledR}$ Premix Ex Taq ${ }^{\mathrm{TM}}$ II were from Takara Biotechnology (Dalian, China); RIPA lysis buffer was from Beyotime Biotech (Shanghai, China); mouse anti-receptor for advanced glycation end-products (RAGE) antibody and phycoerythrin (PE)-conjugated antibody against CD34 were from Santa Cruz Biotechnology, Inc. (Santa Cruz, CA, USA); mouse anti-GAPDH antibody was from Abcam (Cambridge, UK); PE-conjugated antibody against CD29 was from BioLegend Inc. (San Diego, CA, USA); the Detoxi-Gel column was from Pierce (Rockford, IL, USA); the ECL kit was from Applygen Technologies Inc. (Beijing, China). All other chemicals and reagents were purchased from commercial sources and were of analytical grade.

MSC isolation and culture conditions. All animal procedures were approved by institutionally approved protocols and guidelines. After the rats (Sprague-Dawley, 4 weeks of age, male) were sacrificed by the controlled inhalation of $\mathrm{CO}_{2}$, the hind legs were removed, the soft tissue was removed and bone marrow from the femurs was flushed out with serum-free DMEM. The cells were then cultured in H-DMEM with $10 \%$ FBS and $1 \%$ penicillin/streptomycin at $37^{\circ} \mathrm{C}$ in a humidified atmosphere containing $5 \% \mathrm{CO}_{2}$. The medium was first changed after 2 days and subsequently every 2 to 3 days. MSCs were purified by plastic adherence and expanded in culture flasks. Third or fourth passage cells were used for all experiments.

AOPP preparation. AOPPs-BSA was prepared as described previously (17). Briefly, BSA $(100 \mathrm{mg} / \mathrm{ml})$ was incubated with $200 \mathrm{mM}$ hypochlorous acid (HOCl) for $30 \mathrm{~min}$ at $37 \%$ and dialyzed overnight against PBS to remove free $\mathrm{HOCl}$. AOPPs-BSA was passed through a Detoxi-Gel column to remove contaminated endotoxin. Endotoxin levels in the prepa- ration were determined using the amebocyte lysate assay kit and were found to be $<0.25 \mathrm{EU} / \mathrm{ml}$. AOPP content in the preparation was then determined. Briefly, $200 \mu \mathrm{l}$ of sample or chloramine-T were placed in a 96-well plate, followed by $20 \mu 1$ of acetic acid. The absorbance at $340 \mathrm{~nm}$ was determined immediately in a microplate reader. AOPP content was $57.6 \pm 4.9 \mathrm{nmol} / \mathrm{mg}$ protein in the AOPPs-BSA and $0.24 \pm 0.09 \mathrm{nmol} / \mathrm{mg}$ protein in the native BSA preparation.

Flow cytometry. The MSCs were analyzed by flow cytometry to determine the pluripotent cell characteristics. Following trypsinization, the cells were resuspended in PBS reaching a concentration of $3.0 \times 10^{6} / \mathrm{ml}$. Cell suspension per sample $(100 \mu \mathrm{l})$ was then incubated with PE-conjugated antibodies against CD34, and CD29. The cells were incubated in the dark for $30 \mathrm{~min}$ at $4^{\circ} \mathrm{C}$. The control samples were incubated with PE-conjugated isotype-matched antibodies. Following incubation, the cells were washed with PBS and centrifuged to remove unbound antibody. The cells were resuspended in $400 \mu \mathrm{l}$ PBS and evaluated by flow cytometry (BeckmanCoulter, Brea, CA, USA).

Adipogenic differentiation assay. MSCs were seeded at a density of $5 \times 10^{5}$ cells/well in 6 -well plates and cultured in commercially available adipogenic differentiation medium for 3 weeks. For Oil Red O staining, the cells were fixed with $4 \%$ paraformaldehyde, washed in water and stained with a $0.6 \%(\mathrm{w} / \mathrm{v})$ Oil Red O solution for $1 \mathrm{~h}$ at room temperature, followed by washing with water to remove unbound dye. Oil Red O staining of lipid droplets was analyzed under a phase-contrast inverted microscope (Olympus, Japan).

Osteogenic differentiation assay. MSCs were seeded at $5 \times 10^{5}$ cells/well in 6 -well plates and were stimulated with osteogenic differentiation medium as previously described (23) for 3 weeks. To evaluate the effects of AOPPs on the osteogenic differentiation of MSCs, the cells were cultured in the induction medium for 2 weeks, followed by stimulation in $10 \%$ FBS-DMEM with the addition of BSA $(200 \mu \mathrm{g} / \mathrm{ml})$ or AOPPs $(200 \mu \mathrm{g} / \mathrm{ml})$ for 1 week. For the detection of osteogenic differentiation, bone nodule formation was examined by alizarin red staining. Briefly, the cells were fixed with $95 \%$ ethanol for $10 \mathrm{~min}$ and washed 3 times with PBS. Alizarin red solution $(1 \%)$ was added to the cells for $30 \mathrm{~min}$ at $37^{\circ} \mathrm{C}$, and then washed with PBS. Bone nodule formation was observed under a phase-contrast microscope.

Cell proliferation assay. The MSCs were plated at $10^{4}$ cells/well in 96-well plates and cultured for 2 days in $10 \%$ FBS-DMEM. Then they were serum-deprived overnight and incubated with control medium, BSA $(200 \mu \mathrm{g} / \mathrm{ml})$ or AOPPs $(50-400 \mu \mathrm{g} / \mathrm{ml})$ for 3 days, or with AOPPs $(200 \mu \mathrm{g} / \mathrm{ml})$ for different periods of time $(0,24,48,72 \mathrm{~h})$. MTT assay was used to evaluate the viability of the MSCs. In brief, MSCs in 96-well plates were washed twice with 0.01 M PBS, then incubated in $100 \mu \mathrm{l}$ of FBS-free DMEM supplemented with $10 \mu \mathrm{l}$ of $5 \mathrm{mg} / \mathrm{ml} \mathrm{MTT}$ solution at $37^{\circ} \mathrm{C}$. After $4 \mathrm{~h}$, the supernatant was carefully removed, and the crystals were dissolved by incubation with $150 \mu 1$ of DMSO for $20 \mathrm{~min}$. The plates were shaken for $5 \mathrm{~min}$ and the absorbance at $570 \mathrm{~nm}$ was measured 
in a microplate reader. The results are expressed as absorbance (OD at $570 \mathrm{~nm}$ ).

Alkaline phosphatase (ALP) activity assay. The MSCs were seeded at $10^{5}$ cells/well in 24 -well plates and stimulated with osteogenic differentiation medium for 2 weeks. The cells were then serum-deprived overnight and incubated under various culture conditions as described above for 3 days. Cell extract was then prepared using RIPA lysis buffer. ALP activity in the cell lysates was assayed at the end of the incubation time with $10 \mathrm{mM}$ p-nitrophenyl phosphate in $0.15 \mathrm{M}$ sodium carbonate buffer ( $\mathrm{pH} 10.3$ ) and $1 \mathrm{mM} \mathrm{MgCl}{ }_{2}$ as previously described (24). The enzyme activity was normalized against the cellular protein concentration and expressed as U/g protein. Protein concentrations were determined using the BCA assay kit.

Determination of ROS generation. Intracellular ROS generation was measured by flow cytometry with the probe DCFH-DA. Briefly, MSCs grown in 10-cm plates were subjected to various culture conditions as described above for $2 \mathrm{~h}$. The medium was replaced by control medium with $10 \mu \mathrm{M}$ DCFH-DA for 30 min in the dark. Intracellular ROS generation was visualized under a fluorescent microscope (Olympus, Tokyo, Japan). DCF fluorescence was measured on a flow cytometer. Data were normalized to the control values.

Gene expression by real-time polymerase chain reaction (PCR). MSCs for examining ALP and collagen I mRNA levels were stimulated with osteogenic differentiation medium for 1 week; they were then serum-deprived overnight and subjected to various culture conditions as described above for 3 days. Cells for RAGE were only subjected to various culture conditions as described above for 3 days. After this period, total RNA was extracted using TRIzol reagent according to the manufacturer's instructions. cDNA was reverse-transcribed from $0.8 \mu \mathrm{g}$ of total RNA using the PrimeScript one step RT-PCR kit. The primers used were as follows: ALP forward, 5'-AGATGGACAAGT TCCCCTTTG-3' and reverse, 5'-ACACAAGTAGGCAGTG GCAGT-3'; collagen I forward, 5'-GTGGAAACCTGATGTAT GCTTG-3' and reverse, 5'-ATGACTTCTGCGTCTGCGTCTG GTGATA-3'; RAGE forward, 5'-ACTCACAGCCAATGTCCC TAA-3' and reverse, 5'-CTTTGCCATCAGGAATCAGAG-3'; and $\beta$-actin forward, 5'-TTCTACAATGAGCTGCGTGT GGC-3' and reverse, 5'-CTCATAGCTCTTCTCCAGGGA GGA-3'. Real-time PCR was carried out in a Real-Time PCR System (Stratagene/Agilent Technologies, Wilmington, DE, USA) using SYBR Premix Ex Taq II. The cycling conditions were as follows: $95^{\circ} \mathrm{C}$ for $2 \mathrm{~min}$ and 40 cycles of $95^{\circ} \mathrm{C}$ for $5 \mathrm{sec}, 60^{\circ} \mathrm{C}$ for $30 \mathrm{sec}$. The value of $2^{-\Delta \Delta \mathrm{Ct}}$ represents the relative level of target gene expression.

Western blot analysis of RAGE. The MSCs were stimulated with various culture conditions as described above for 3 days following starvation overnight in serum-free medium. Proteins were then extracted from the MSCs using RIPA lysis buffer followed by centrifugation at $4^{\circ} \mathrm{C}, 12,000 \mathrm{rpm}$ for $20 \mathrm{~min}$. Protein concentration was determined by BCA assay. Proteins were then separated by SDS-PAGE and electrotransferred onto a PVDF membrane. The membrane was incubated with mouse anti-RAGE (1:500) and mouse anti-GAPDH antibodies (1:500) overnight at $4^{\circ} \mathrm{C}$. The membrane was washed 3 times with TBST and incubated with HRP-conjugated secondary IgG for $50 \mathrm{~min}$. The bands were detected using the ECL chemiluminescence detection system.

Statistical analysis. All values are expressed as the mean \pm SD. Each experiment was repeated at least 3 times. One-way ANOVA followed by the Scheffe's test or Dunnett's T3 (equal variances not assumed) was performed for multiple comparisons. A P-value $<0.05$ was considered to indicate a statistically significant difference.

\section{Results}

Isolation and identification of MSCs. MSCs were isolated from rat femur bone marrow and formed elongated spindle or polygon shapes. Passage $3 \mathrm{MSCs}$ were detected by flow cytometry and the results revealed that the cells were negative for CD34 (Fig. 1A) and positive for CD29 (Fig. 1B). The former is a marker of hematopoietic stem cells and the latter is a characteristic cell surface marker of MSCs. Following stimulation in adipogenic differentiation and osteogenic differentiation medium, lipid droplets in the cells (Fig. 1C) and bone nodules (Fig. 1D) were observed.

Effects of AOPPs on proliferation of MSCs. MSC proliferation was evaluated by MTT assay. As shown in Fig. 2A, AOPPs (50-400 $\mu \mathrm{g} / \mathrm{ml}$ ) significantly inhibited the proliferation of the MSCs within 3 days compared with the control medium and the unmodified BSA preparation. Furthermore, the inhibitory effects on proliferation were observed in the MSCs stimulated with $200 \mu \mathrm{g} / \mathrm{ml}$ of AOPPs for 24-72 h (Fig. 2B). These results indicated that AOPPs inhibited MSC proliferation in a doseand time-dependent manner.

Effects of AOPPs on osteogenic differentiation of MSCs. To investigate the effect of AOPPs on MSC osteogenic differentiation, ALP activity and the mRNA expression of ALP and collagen I were detected. The cells were stimulated as described above. As shown in Fig. 3A, AOPPs (100-400 $\mu \mathrm{g} / \mathrm{ml})$ decreased ALP activity in the MSCs; a time-dependent decrease in ALP activity was observed in the cells exposed to AOPPs (Fig. 3B) compared with those cultured in the control medium and BSA. We also found that the exposure of MSCs to AOPPs resulted in a significant decrease in the mRNA expression of ALP (Fig. 4A) and collagen I (Fig. 4B). Although bone nodule formation was observed in the control group, only slight bone nodule formation was observed in the cells exposed to AOPPs (Fig. 5) after alizarin red staining. These data indicate that AOPPs inhibit the osteogenic differentiation of MSCs.

Effects of AOPPs on ROS generation in MSCs. ROS generation was examined by the detection of DCF fluorescence by flowcytometry analysis. The increase in ROS generation in the MSCs was observed visually in the cells exposed to AOPPs compared with the control and BSA-treated cells (Fig. 6A-F); this increase in ROS occurred in a dose-dependent manner (Fig. 6G).

Effects of AOPPs on RAGE mRNA and protein expression in $M S C s$. RAGE is considered a receptor of AOPPs, and oxidative stress may be activated with their binding (7). The mRNA 

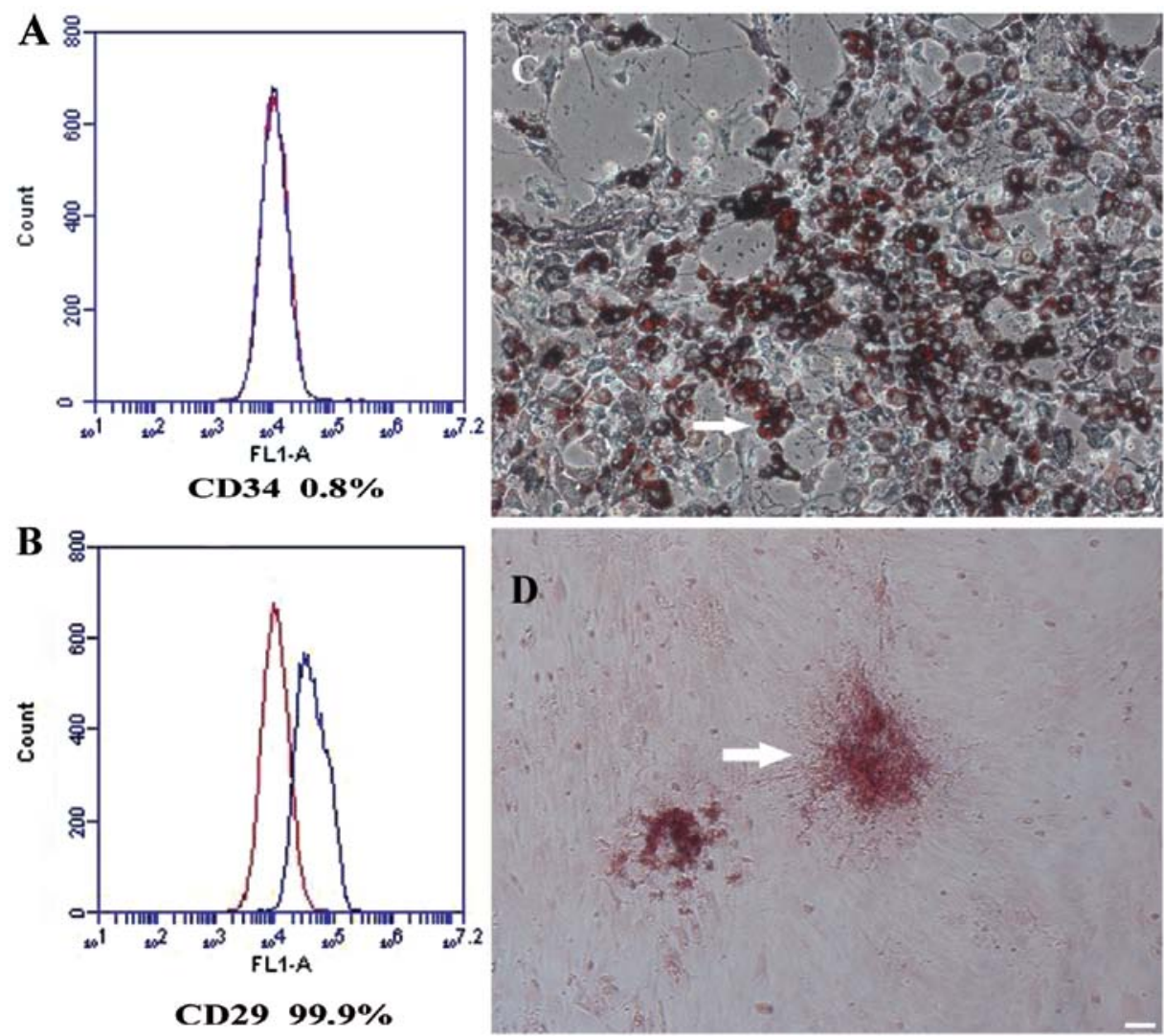

Figure 1. Identification of mesenchymal stem cells (MSCs). The surface markers, CD34 and CD29, in the MSCs were detected by flow cytometry. MSCs were stimulated with adipogenic and osteogenic differentiation medium for 3 weeks. Lipid droplets were detected by Oil Red O staining. Bone nodule formation was examined by alizarin red staining. The MSCs were (A) negative for CD34 and (B) postivie for CD29. (C) Lipid droplets (arrows) and (D) bone nodules (arrows) were also observed following stimulation. Scale bar, $100 \mu \mathrm{m}$.
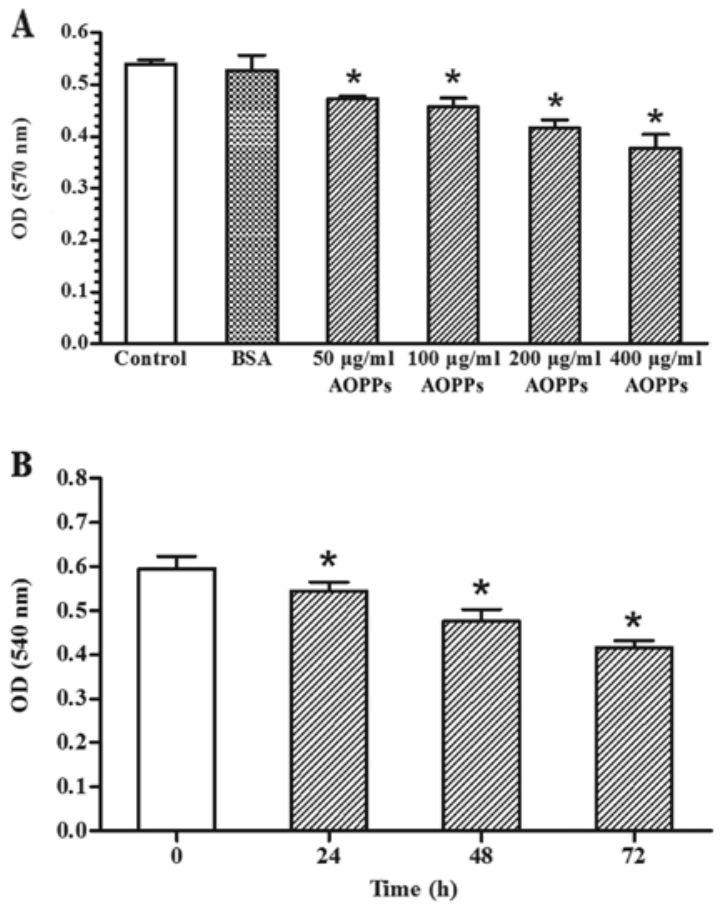

Figure 2. Effect of advanced oxidation protein products (AOPPs) on the proliferation of mesenchymal stem cells (MSCs). MSCs were incubated with control medium, bovine serum albumin (BSA) or indicated concentrations of AOPPs for the indicated periods of time. MTT assay was used for detecting cell proliferation. AOPPs inhibited MSC proliferation in (A) a concentrationand (B) a time-dependent manner. Data are presented as the means \pm SD. $\mathrm{P}<0.01,{ }^{*} \mathrm{P}<0.01$ vs. control.
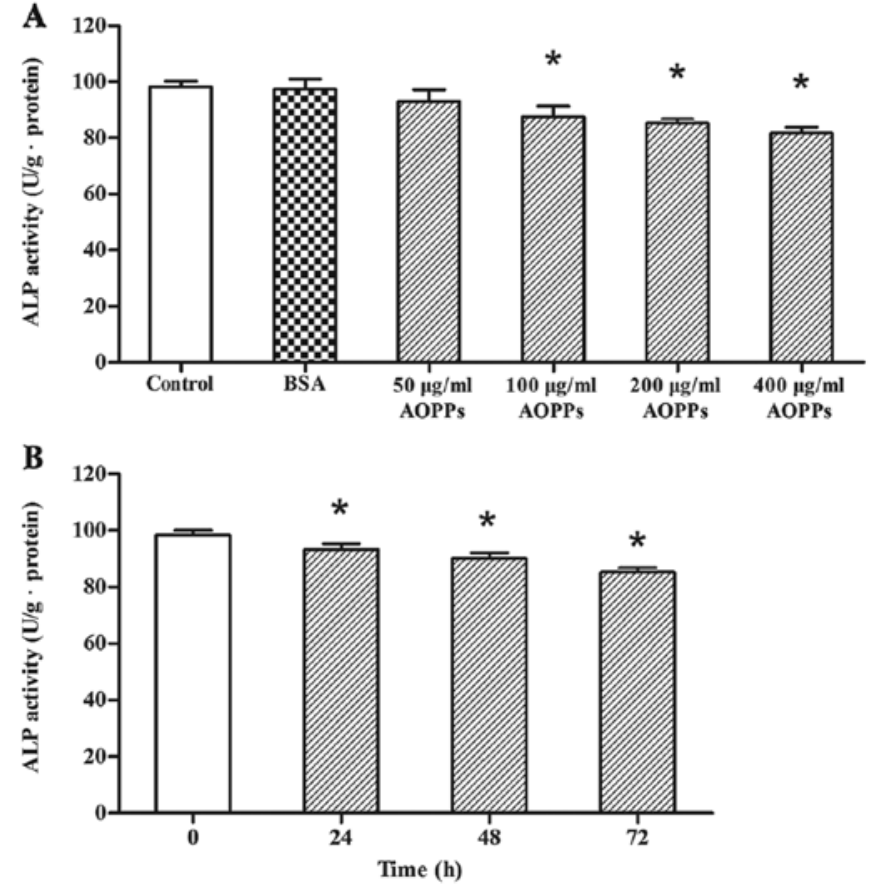

Figure 3. Effect of advanced oxidation protein products (AOPPs) on alkaline phosphatase (ALP) activity in mesenchymal stem cells (MSCs). MSCs were stimulated with osteogenic differentiation medium for 2 weeks, then incubated with control medium, bovine serum albumin (BSA) or indicated concentrations of AOPPs for 3 days. (A) AOPPs (100-400 $\mu \mathrm{g} / \mathrm{ml}$ ) decreased ALP activity in the MSCs; (B) AOPPs decreased ALP activity in a time-dependent manner. Data are presented as the means $\pm \mathrm{SD}$. $\mathrm{P}<0.01,{ }^{\mathrm{N}} \mathrm{P}<0.01$ vs. control. 
A

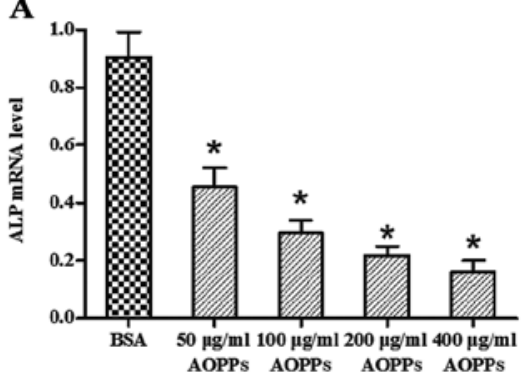

B

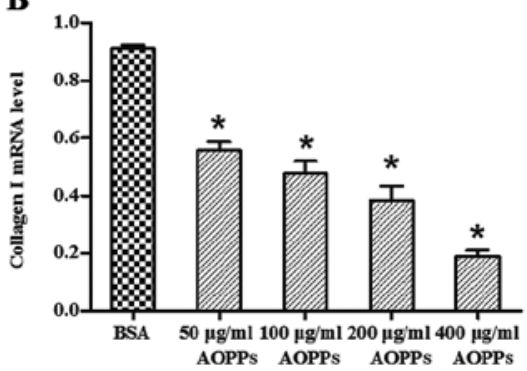

C

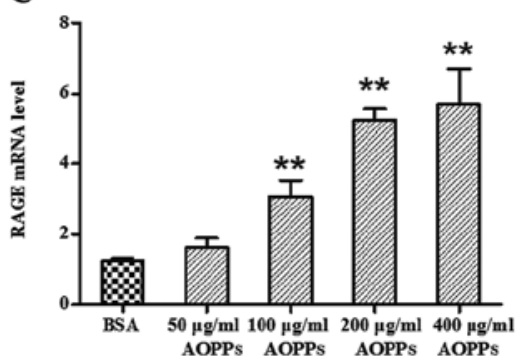

Figure 4. Effect of advanced oxidation protein products (AOPPs) on the expression of alkaline phosphatase (ALP), collagen I, RAGE mRNA. Mesenchymal stem cells (MSCs) were incubated with control medium, bovine serum albumin (BSA) or indicated concentrations of AOPPs for the indicated periods of time. mRNA levels were detected by real-time PCR. AOPPs inhibited the mRNA expression of (A) ALP, (B) collagen I and (C) RAGE. Data are presented as the means \pm SD. (A and B) $\mathrm{P}<0.01,(\mathrm{C}) \mathrm{P}<0.05,{ }^{*} \mathrm{P}<0.01$ vs. control, ${ }^{* *} \mathrm{P}<0.05$ vs. control.
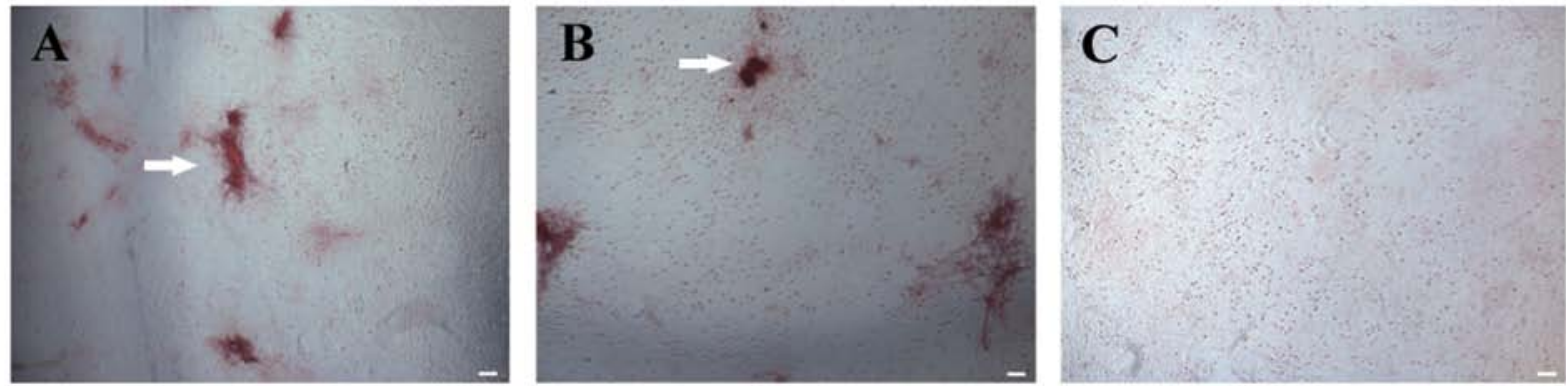

Figure 5. Effect of advanced oxidation protein products (AOPPs) on bone nodule formation of mesenchymal stem cells (MSCs). MSCs were cultured in induction medium for 2 weeks, and then stimulated in medium with the addition of bovine serum albumin (BSA) $(200 \mu \mathrm{g} / \mathrm{ml})$ or AOPPs $(200 \mu \mathrm{g} / \mathrm{ml})$ for $1 \mathrm{week}$. Bone nodules were observed by alizarin red staining. Bone nodule formation was observed in (A) the controls and (B) the BSA-treated cells, indicated by arrows; (C) however, only slight bone nodule formation was observed in the cells exposed to AOPPs. Scale bar, $200 \mu \mathrm{m}$.
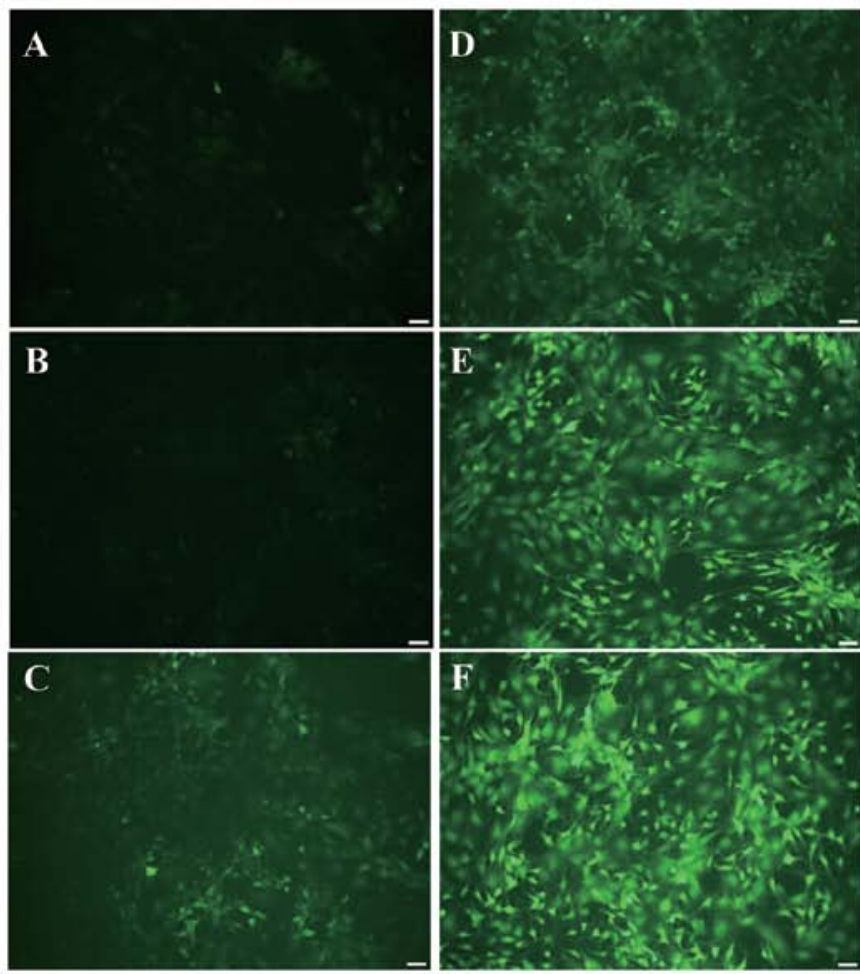

$\mathbf{G}$

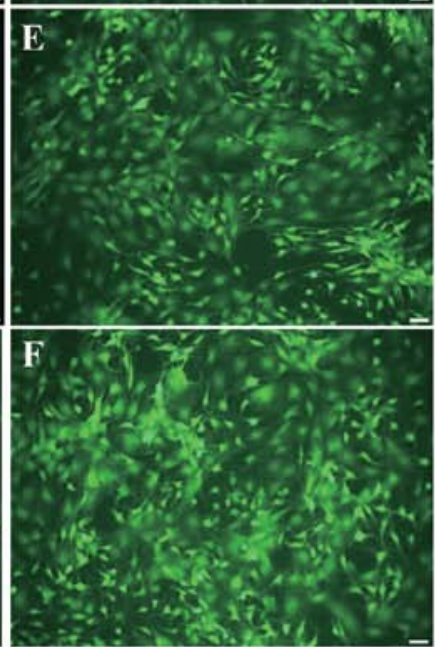

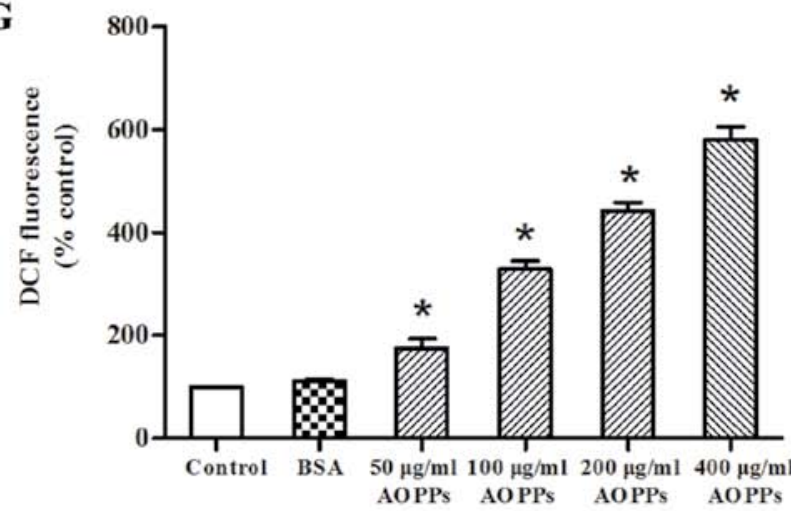

Figure 6. Effect of advanced oxidation protein products (AOPPs) on the generation of reactive oxygen species (ROS) in mesenchymal stem cells (MSCs). MSCs were incubated with control medium, bovine serum albumin (BSA) or indicated concentrations of AOPPs for $2 \mathrm{~h}$. Intracellular ROS generation was measured with the probe DCFH-DA, and visualized using a fluorescent microscope. (A) Control; (B) BSA; (C) $50 \mu \mathrm{g} / \mathrm{ml}$ AOPPs; (D) $100 \mu \mathrm{g} / \mathrm{ml} \mathrm{AOPPs}$; (E) $200 \mu \mathrm{g} / \mathrm{ml}$ AOPPs; (F) $400 \mu \mathrm{g} / \mathrm{ml}$ AOPPs. DCF fluorescence was measured on a flow cytometer. AOPPs induced ROS generation (as visualized by green fluorescence) compared with the control and BSA (A-F), in a dose-dependent manner (G). Data are presented as the means \pm SD. $\mathrm{P}<0.01,{ }^{*} \mathrm{P}<0.01 \mathrm{vs}$. control. Scale bar, $100 \mu \mathrm{m}$. 


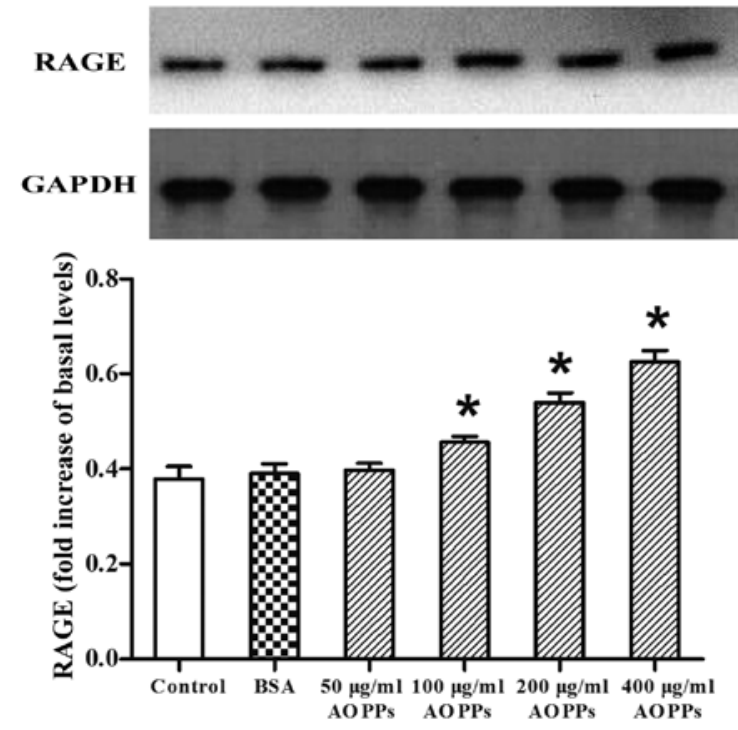

Figure 7. Effect of advanced oxidation protein products (AOPPs) on the protein expression of RAGE. Mesenchymal stem cells (MSCs) were incubated with control medium, bovine serum albumin (BSA) or indicated concentrations of AOPPs for 3 days. Protein levels were detected by western blot analysis. AOPPs $(100-400 \mu \mathrm{g} / \mathrm{ml})$ upregulated the protein level of RAGE. Data are presented as the means $\pm \mathrm{SD}$. $\mathrm{P}<0.05,{ }^{*} \mathrm{P}<0.05$ vs. control.

and protein expression of RAGE in the MSCs was measured by real-time PCR and western blot analysis, respectively. As shown in Fig. 4C and 7, exposure to AOPPs, as opposed to exposure to $\mathrm{BSA}$, increased the mRNA and protein expression of RAGE.

\section{Discussion}

Bone mass is maintained locally by the balance between osteoclastic bone resorption and osteoblastic bone formation. The latter process is carried out by osteoblasts whose number and activity is determined by the proliferation and differentiation of osteoblast precursors derived from MSCs (25). Hence, MSCs play an important role in the development of osteoporosis. The cells used in this study were positive for the cell-surface marker, CD29, but negative for CD34, and had the potential to differentiate into adipose cells and osteoblasts, suggesting that these cells were MSCs.

Increasing evidence indicates that AOPPs, as a novel marker of oxidative stress, are involved in various diseases, such as renal failure (5), diabetes mellitus (9), coronary artery disease (12) and osteoporosis (14), and have various biological activities. The data presented in this study demonstrate that AOPPs inhibit the proliferation and osteogenic differentiation of MSCs. We found that AOPPs inhibited the proliferation and ALP activity in MSCs, as well as ALP and collagen I gene expression. In addition, AOPPs increased the mRNA and protein expression of RAGE, as well as the generation of ROS. These results suggest that AOPPs exert adverse effects on MSCs through the RAGE-ROS pathway.

It has been reported that AOPPs inhibit cell proliferation in human gingival fibroblasts (26) and osteoblasts (17); however, it also has been shown that AOPPs (50-400 $\mu \mathrm{g} / \mathrm{ml})$ induce adventitial fibroblast proliferation (27). In the present study, we found that AOPPs inhibited MSC proliferation in a dose- and time-dependent manner. These results indicate that AOPPs react differently according to different cell types and doses.
The developmental sequence of osteoblast differentiation can be characterized in 3 stages, including cell proliferation, extracellular matrix production and mineralization. During proliferation, the production of collagen I initially occurs, followed by an increased in the expression of ALP and calcium deposition (28). Collagen I comprises approximately $90 \%$ of the organic material as the most abundant protein component of the bone matrix. The enhanced expression of ALP metabolizes calcium phosphate into insoluble phosphate salts, thus mediating calcification (29). In this study, AOPPs significantly decreased ALP and collagen I mRNA levels and inhibited ALP secretion by MSCs in a dose- and time-dependent manner. Using alizarin red staining, we also observed that dystrophic mineralization occurred in the MSCs exposed to AOPPs compared with the controls. These data indicate that AOPPs inhibit MSC osteogenic differentiation.

AOPPs have similar biological characteristics to those of advanced glycation end-products (AGEs), and bind to the same receptor, RAGE (8). To investigate the potential mechanisms behind the adverse effects AOPPs on MSCs, we examined ROS levels and RAGE expression in the MSCs exposed to AOPPs. ROS are products of oxidative stress, such as $\mathrm{O}^{2-}, \mathrm{H}_{2} \mathrm{O}_{2}$ and $-\mathrm{OH}$, which have been implicated in the regulation of diverse cellular functions, including intracellular signaling, transcriptional activation, proliferation and apoptosis. A number of studies have suggested that oxidative stress is involved in the progression of osteoporosis. Oxidative stress suppresses the osteoblastic differentiation of MSCs through ERK and NF- $\kappa \mathrm{B}$ (30). Receptor activator of NF- $\kappa \mathrm{B}$ ligand (RANKL)-mediated ROS production may promote the differentiation of MSCs into osteoclasts as an intracellular signal mediator (31). A reduction in ROS permits the restoration of osteoblastic markers, specifically the induction of osteoprotegerin and osteocalcin (32). Our results also demonstrated that AOPPs increased ROS generation in the MSCs in a dose-dependent manner, indicating that ROS production induced by AOPPs may participate in the inhibition of proliferation and the osteogenic differentiation of MSCs.

RAGE is capable of binding to multiple ligands, including AGEs, AOPPs, high-mobility group box-1 and $\beta$-sheet fibrils (33). AGEs-RAGE interaction induces the generation of ROS through NADPH oxidase, resulting in the apoptosis of osteoblasts/MSCs (34) and in the inhibition of the proliferation and differentiation of osteoblasts/MSCs (35). RAGE overexpression by lentiviral transfection has been shown to inhibit osteoblast proliferation through the suppression of the Wnt, PI3K and ERK pathways (36). Studies using RAGE knockout mice have also shown increased bone mass and bone biomechanical strength and a decreased number of osteoclasts in $\mathrm{RAGE}^{-/}$mice compared with wild-type mice (37). These data indicate that RAGE plays a modulatory role in the development of osteoporosis. In this study, we also observed an increased expression of RAGE at the mRNA and protein level as the dose of AOPPs increased. Therefore, taking all these data into consideration, we hypothesized that AOPPs may inhibit the proliferation and osteogenic differentiation of MSCs by upregulating RAGE expression following an increase in ROS production.

In conclusion, our data indicate that AOPPs inhibit the proliferation and osteogenic differentiation of MSCs. We also observed an increase in RAGE expression and ROS generation. Although the association between the increased expression of 
RAGE and increased ROS generation induced by AOPPs was not examined in detail, considering the similar biological characteristics of AOPPs and AGEs and taking into account the data from previous studies, it can be concluded that AOPPs inhibit the proliferation and osteogenic differentiation of MSCs through a AOPPs-RAGE-ROS pathway. This may provide a new perspective as to the development of osteoporosis, and further suggests that AOPPs may be an effective clinical indicator of osteoporosis.

\section{Acknowledgements}

This study was supported by a grant from the National Natural Science Foundation of China (no. 81270966).

\section{References}

1. Wongdee $\mathrm{K}$ and Charoenphandhu N: Osteoporosis in diabetes mellitus: possible cellular and molecular mechanisms. World J Diabetes 2: 41-48, 2011.

2. Cervellati C, Bonaccorsi G, Cremonini E, Bergamini CM, Patella A, Castaldini C, Ferrazzini S, Capatti A, Picarelli V, Pansini FS and Massari L: Bone mass density selectively correlates with serum markers of oxidative damage in postmenopausal women. Clin Chem Lab Med 51: 333-338, 2013.

3. Fatokun AA, Stone TW and Smith RA: Responses of differentiated MC3T3-E1 osteoblast-like cells to reactive oxygen species. Eur J Pharmacol 587: 35-41, 2008.

4. Sheweita SA and Khoshhal KI: Calcium metabolism and oxidative stress in bone fractures: role of antioxidants. Curr Drug Metab 8: 519-525, 2007.

5. Witko-Sarsat V, Friedlander M, Capeillere-Blandin C, Nguyen-Khoa T, Nguyen AT, Zingraff J, Jungers P and DescampsLatscha B: Advanced oxidation protein products as a novel marker of oxidative stress in uremia. Kidney Int 49: 1304-1313, 1996.

6. Witko-Sarsat V, Friedlander M, Nguyen Khoa T, CapeillereBlandin C, Nguyen AT, Canteloup S, Dayer JM, Jungers P, Drueke T and Descamps-Latscha B: Advanced oxidation protein products as novel mediators of inflammation and monocyte activation in chronic renal failure. J Immunol 161: 2524-2532, 1998

7. Guo ZJ, Niu HX, Hou FF, Zhang L, Fu N, Nagai R, Lu X, Chen BH, Shan YX, Tian JW, Nagaraj RH, Xie D and Zhang X: Advanced oxidation protein products activate vascular endothelial cells via a RAGE-mediated signaling pathway. Antioxid Redox Signal 10: 1699-1712, 2008.

8. Piwowar A: Advanced oxidation protein products. Part I. Mechanism of the formation, characteristics and property. Pol Merkur Lekarski 28: 166-169, 2010 (In Polish).

9. Piwowar A, Knapik-Kordecka M and Warwas M: AOPP and its relations with selected markers of oxidative/antioxidative system in type 2 diabetes mellitus. Diabetes Res Clin Pract 77: 188-192, 2007.

10. Cumaoglu A, Cevik C, Rackova L, Ari N and Karasu C: Effects of antioxidant stobadine on protein carbonylation, advanced oxidation protein products and reductive capacity of liver in streptozotocin-diabetic rats: role of oxidative/nitrosative stress. BioFactors 30: 171-178, 2007.

11. Krzystek-Korpacka M, Neubauer K, Berdowska I, Boehm D, Zielinski B, Petryszyn P, Terlecki G, Paradowski L and Gamian A: Enhanced formation of advanced oxidation protein products in IBD. Inflamm Bowel Dis 14: 794-802, 2008.

12. Kaneda H, Taguchi J, Ogasawara K, Aizawa T and Ohno M: Increased level of advanced oxidation protein products in patients with coronary artery disease. Atherosclerosis 162: 221-225, 2002

13. Collet C, Schiltz C, Geoffroy V, Maroteaux L, Launay JM and de Vernejoul MC: The serotonin 5-HT2B receptor controls bone mass via osteoblast recruitment and proliferation. FASEB J 22 . 418-427, 2008

14. Zhang YB, Zhong ZM, Hou G, Jiang H and Chen JT: Involvement of oxidative stress in age-related bone loss. J Surg Res 169: e37-e42, 2011

15. Choi EM and Kim YH: Hesperetin attenuates the highly reducing sugar-triggered inhibition of osteoblast differentiation. Cell Biol Toxicol 24: 225-231, 2008.

16. Lee KH and Choi EM: Myricetin, a naturally occurring flavonoid, prevents 2-deoxy-D-ribose induced dysfunction and oxidative damage in osteoblastic MC3T3-E1 cells. Eur J Pharmacol 591: $1-6,2008$.
17. Zhong ZM, Bai L and Chen JT: Advanced oxidation protein products inhibit proliferation and differentiation of rat osteoblastlike cells via NF-kappaB pathway. Cell Physiol Biochem 24: $105-114,2009$

18. Rodan GA and Martin TJ: Therapeutic approaches to bone diseases. Science 289: 1508-1514, 2000.

19. Pittenger MF, Mackay AM, Beck SC, Jaiswal RK, Douglas R, Mosca JD, Moorman MA, Simonetti DW, Craig S and Marshak DR: Multilineage potential of adult human mesenchymal stem cells. Science 284: 143-147, 1999.

20. Long MW: Osteogenesis and bone-marrow-derived cells. Blood Cells Mol Dis 27: 677-690, 2001

21. Dalle Carbonare L, Valenti MT, Zanatta M, Donatelli L and Lo Cascio V: Circulating mesenchymal stem cells with abnormal osteogenic differentiation in patients with osteoporosis. Arthritis Rheum 60: 3356-3365, 2009.

22. Benisch P, Schilling T, Klein-Hitpass L, Frey SP, Seefried L, Raaijmakers N, Krug M, Regensburger M, Zeck S, Schinke T, Amling M, Ebert R and Jakob F: The transcriptional profile of mesenchymal stem cell populations in primary osteoporosis is distinct and shows overexpression of osteogenic inhibitors. PloS One 7: e45142, 2012.

23. Kume S, Kato S, Yamagishi S, Inagaki Y, Ueda S, Arima N, Okawa T, Kojiro $M$ and Nagata K: Advanced glycation endproducts attenuate human mesenchymal stem cells and prevent cognate differentiation into adipose tissue, cartilage, and bone. J Bone Miner Res 20: 1647-1658, 2005.

24. Farley JR and Jorch UM: Differential effects of phospholipids on skeletal alkaline phosphatase activity in extracts, in situ and in circulation. Arch Biochem Biophys 221: 477-488, 1983.

25. Harada S and Rodan GA: Control of osteoblast function and regulation of bone mass. Nature 423: 349-355, 2003.

26. Deng YQ, Fu Y, Su XP and Tang ZY: Biologic effects of advanced oxidative protein products on the human gingival fibroblasts. Zhonghua Kou Qiang Yi Xue Za Zhi 44: 270-273, 2009 (In Chinese).

27. Ouyang P, Liu S, Bei W, Lai W, Hou F and Xu A: Effects of flavone from leaves of Diospyros kaki on adventitial fibroblasts proliferation by advanced oxidation protein products in vitro. Zhong Yao Cai 27: 186-188, 2004 (In Chinese).

28. Siggelkow H, Rebenstorff K, Kurre W, Niedhart C, Engel I, Schulz H, Atkinson MJ and Hufner M: Development of the osteoblast phenotype in primary human osteoblasts in culture: comparison with rat calvarial cells in osteoblast differentiation. J Cell Biochem 75: 22-35, 1999.

29. Beck GR Jr, Sullivan EC, Moran E and Zerler B: Relationship between alkaline phosphatase levels, osteopontin expression, and mineralization in differentiating MC3T3-E1 osteoblasts. J Cell Biochem 68: 269-280, 1998.

30. Bai XC,Lu D, Bai J,Zheng H, Ke ZY,Li XM and Luo SQ: Oxidative stress inhibits osteoblastic differentiation of bone cells by ERK and NF-kappaB. Biochem Biophys Res Commun 314: 197-207, 2004.

31. Lee NK, Choi YG, Baik JY, Han SY, Jeong DW, Bae YS, Kim N and Lee SY: A crucial role for reactive oxygen species in RANKLinduced osteoclast differentiation. Blood 106: 852-859, 2005.

32. Barbagallo I, Vanella A, Peterson SJ, Kim DH, Tibullo D, Giallongo C, Vanella L, Parrinello N, Palumbo GA, Di Raimondo F, Abraham NG and Asprinio D: Overexpression of heme oxygenase-1 increases human osteoblast stem cell differentiation. J Bone Mineral Metab 28: 276-288, 2010

33. Yan SF, Ramasamy R and Schmidt AM: The RAGE axis: a fundamental mechanism signaling danger to the vulnerable vasculature. Circ Res 106: 842-853, 2010.

34. Wautier MP, Chappey O, Corda S, Stern DM, Schmidt AM and Wautier JL: Activation of NADPH oxidase by AGE links oxidant stress to altered gene expression via RAGE. Am J Physiol Endocrinol Metab 280: E685-E694, 2001.

35. Yamagishi S: Role of advanced glycation end products (AGEs) in osteoporosis in diabetes. Curr Drug Targets 12: 2096-2102, 2011.

36. Li G, Xu J and Li Z: Receptor for advanced glycation end products inhibits proliferation in osteoblast through suppression of Wnt, PI3K and ERK signaling. Biochem Biophys Res Commun 423: 684-689, 2012.

37. Ding KH, Wang ZZ, Hamrick MW, Deng ZB, Zhou L, Kang B, Yan SL, She JX, Stern DM, Isales CM and Mi QS: Disordered osteoclast formation in RAGE-deficient mouse establishes an essential role for RAGE in diabetes related bone loss. Biochem Biophys Res Commun 340: 1091-1097, 2006. 